\title{
Stereo-preference in the degradation of the erythro and threo isomers of $\beta$-0-4-type lignin model compounds in oxidation processes III: in the reaction with chlorine- and manganese-based oxidants
}

\author{
Pattaraporn Posoknistakul ${ }^{1,2} \cdot$ Satoru Akiho ${ }^{1,3} \cdot$ Takuya Akiyama $^{1} \cdot$ Tomoya Yokoyama $^{1}$ (D $\cdot$ Yuji Matsumoto $^{1}$
}

Received: 28 December 2017 / Accepted: 3 March 2018 / Published online: 20 March 2018

(c) The Japan Wood Research Society 2018

\begin{abstract}
We examined which isomer, the erythro or threo, of a non-phenolic $\beta$-O-4-type lignin model compound is stereo-preferentially oxidized in hypochlorite, chlorite, manganese dioxide, or permanganate systems. No clear stereo-preference was observed in the hypochlorite or chlorite systems at alkaline, neutral, or acidic $\mathrm{pH}$ except for a slight threo stereo-preference that appeared after the step-wise addition of the oxidizing reagent had been terminated in the neutral or acidic chlorite systems. A clear threo stereo-preference was observed in the manganese dioxide or permanganate systems.
\end{abstract}

Keywords Chlorine dioxide $\cdot$ Chlorite $\cdot$ Hypochlorite $\cdot$ Manganese dioxide $\cdot$ Permanganate

\section{Introduction}

Because the $\beta$-O-4-type is the most abundant substructure in lignin, cleavage of the $\beta-O-4$ bond always controls the delignification and depolymerization of lignin in chemical processes. The diastereomeric erythro $(\boldsymbol{E})$ and threo $(\boldsymbol{T})$ isomers exist in the side chain of the $\beta$ - $O$-4-type substructure (Fig. 1). These isomers show different reactivities in various chemical reactions. An example reaction is the $\beta-O-4$ bond cleavage under alkaline pulping conditions, where the $\beta-O-4$ bond of the $\boldsymbol{E}$ isomer cleaves more rapidly than that of the $\boldsymbol{T}$ isomer [1-6]. However, only a few papers have examined stereo-preferential degradation in oxidation processes [7-10]. Some of them reported stereo-preferential

Tomoya Yokoyama

yokoyama@woodchem.fp.a.u-tokyo.ac.jp

1 Laboratory of Wood Chemistry, Department of Biomaterial Sciences, Graduate School of Agricultural and Life Sciences, The University of Tokyo, 1-1-1 Yayoi, Bunkyo-ku, Tokyo 113-8657, Japan

2 Present Address: Department of Chemical Engineering, Faculty of Engineering, Mahidol University, 25/25 Phutthamonthon 4 Road, Salaya, Phutthamonthon, Nakhon Pathom 73170, Thailand

3 Present Address: Tsukuba Research Center, Kuraray Co., Ltd., 41 Miyukigaoka, Tsukuba, Ibaraki 305-0841, Japan degradation of the $\boldsymbol{T}$ isomer [7, 8], while no clear stereopreference was observed in the others $[9,10]$.

Our previous reports examined the stereo-preferential degradation of the $\boldsymbol{E}$ or $\boldsymbol{T}$ isomer, when each isomer of nonphenolic $\beta$-O-4-type lignin model compounds was individually oxidized by various radical species generated as active oxygen species under oxygen bleaching conditions [11] or by hydroxyl radical and/or its conjugate base, oxyl anion radical, under alkaline hydrogen peroxide bleaching conditions [12]. A slight stereo-preferential degradation of the $\boldsymbol{T}$ isomer was observed at a high $\mathrm{pH}(>13)$. When the electric repulsion between the side chains of the lignin model compounds and a negatively charged active oxygen species, oxyl anion radical, working at high $\mathrm{pH}$, was quenched by lowering the $\mathrm{pH}(<13)$ or structurally modifying the lignin model compounds, a slight stereo-preferential degradation of the $\boldsymbol{E}$ isomer was observed. We concluded, therefore, that the essential stereo-preference of oxyl anion radical is slightly in favor of the $\boldsymbol{E}$ isomer although the reverse stereo-preference can appear depending on the reaction conditions.

In this paper, the stereo-preferential degradation of the $\boldsymbol{E}$ or $\boldsymbol{T}$ isomer was examined when each isomer of the most general non-phenolic $\beta$ - $O$-4-type lignin model compound, 2-(2-methoxyphenoxy)-1-(3,4-dimethoxyphenyl)propane1,3-diol ( $\boldsymbol{I E}$ or $\boldsymbol{I T}$, respectively, Fig. 1), was oxidized in hypochlorite, chlorite, manganese dioxide, or permanganate systems. 
Fig. 1 Structures of the $\beta-O-4$ type lignin subunit, compound $\boldsymbol{I E}$, and compound $\mathbf{I T}$

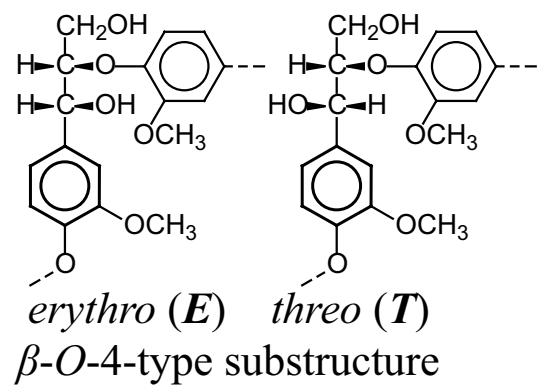

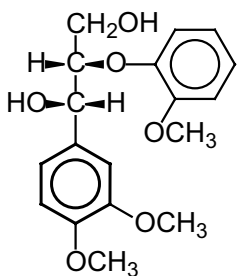

Compound $1 E$ Compound $1 T$

\section{Materials and methods}

\section{Materials}

All chemicals except compounds $\mathbf{I E}$ and $\mathbf{I T}$ were purchased from Wako Pure Chemical Industries, Ltd. (Osaka, Japan), Tokyo Chemical Industry Co., Ltd. (Tokyo, Japan), and Sigma-Aldrich Co. LLC. (St. Louis, MO, USA), and used without further purification. Ultrapure water (Puric-Z, Organo Co., Tokyo, Japan) was used in all the experiments.

The synthesis of compounds $\boldsymbol{I E}$ and $\boldsymbol{I T}$ and their separation were described in our previous reports [11-13]. The structures and purities were confirmed by nuclear magnetic resonance spectroscopy $\left({ }^{1} \mathrm{H}-\mathrm{NMR}\right.$ and ${ }^{13} \mathrm{C}-\mathrm{NMR}$, JNM-A500, JEOL Ltd., Tokyo, Japan). The spectral peaks were indicated in our previous report [11].

\section{Oxidation in hypochlorite systems}

Either compound $\boldsymbol{I E}$ or $\boldsymbol{1 T}(30 \mu \mathrm{mol})$ or both $(15 \mu \mathrm{mol}$ each) were dissolved in $30 \mathrm{~mL}$ of water at an alkaline $\mathrm{pH}$ of 13.3 , neutral $\mathrm{pH}$ of 6.3 , or acidic $\mathrm{pH}$ of 1.0 , adjusted by sodium hydroxide, no reagent, or sulfuric acid $\left(\mathrm{H}_{2} \mathrm{SO}_{4}\right)$, respectively, in a round-bottom glass flask $(50 \mathrm{~mL}$ volume). The flask was placed in a water bath and heated to $70{ }^{\circ} \mathrm{C}$ in the alkaline or neutral reaction, while the acidic reaction was conducted at room temperature. Sodium hypochlorite $(\mathrm{NaClO}, 0.30 \mathrm{mmol}, 10$ times mole amount of compound $\boldsymbol{E}$ or $\boldsymbol{I T}$ ) was added to the reaction solution to initiate the reaction. The same amount of $\mathrm{NaClO}$ was added a total of five times at constant intervals of $10 \mathrm{~min}$, so that the total amount of $\mathrm{NaClO}$ added was $1.5 \mathrm{mmol}$. The reactions were terminated at a reaction time of $60 \mathrm{~min}$ (20 min after the final $\mathrm{NaClO}$ addition).

A portion of the reaction solution was withdrawn at prescribed reaction times to quantify the surviving compound $\boldsymbol{I E}$ or $\boldsymbol{I T}$ and to measure the $\mathrm{pH}$. The detailed workup procedures for quantification were the same as those described in our previous reports [11-13] except for neutralizing the acidic reaction solution with sodium hydrogen carbonate.

\section{Oxidation in chlorite systems}

The reaction was as described above for the $\mathrm{NaClO}$ oxidation except that: (1) sodium chlorite $\left(\mathrm{NaClO}_{2}\right)$ was employed instead of $\mathrm{NaClO}$, maintaining the molar ratio to compound $\boldsymbol{I E}$ or $\boldsymbol{I T}$, and (2) the temperature was $70^{\circ} \mathrm{C}$ for all reactions.

\section{Oxidation in a manganese dioxide system}

Commercially available manganese dioxide $\left(\mathrm{MnO}_{2}\right.$, Wako Pure Chemical Industries, Ltd.) was ground into powder on a mortar and iodometrically titrated, revealing that the oxidation power of the $\mathrm{MnO}_{2}$ powder was $89 \%$ of the theoretical value. The $\mathrm{MnO}_{2}$ powder $(26 \mathrm{mg}, 0.30 \mathrm{mmol}$ ) was aged in $25 \mathrm{~mL}$ of sulfate buffer solution $(0.50 \mathrm{~mol} / \mathrm{L}, \mathrm{pH}$ 1.0) for $120 \mathrm{~min}$ in a round-bottom glass flask $(50 \mathrm{~mL})$ at room temperature. Either compound $\boldsymbol{I E}$ or $\boldsymbol{I T}(6.0 \mu \mathrm{mol})$ was dissolved in $5.0 \mathrm{~mL}$ of another sulfate buffer solution $(0.50 \mathrm{~mol} / \mathrm{L}, \mathrm{pH} 1.0)$, and this buffer solution was added to the buffer solution containing the aged $\mathrm{MnO}_{2}$ powder to initiate the reaction. The reaction was conducted at room temperature for $350 \mathrm{~min}$. The initial concentration of compound $\boldsymbol{I E}$ or $\boldsymbol{I T}$ was $0.20 \mathrm{mmol} / \mathrm{L}$, giving a molar ratio to the $\mathrm{MnO}_{2}$ powder of $1 / 50$.

A portion of the reaction solution was withdrawn to quantify the surviving compound $\boldsymbol{I E}$ or $\boldsymbol{I T}$ at prescribed reaction times. The withdrawn solution was immediately extracted with ethyl acetate (EtOAc) containing an internal standard compound, 3,4,5-trimethoxybenzaldehyde. The water layer was further immediately extracted twice with EtOAc. The combined EtOAc layer was washed with a saturated sodium hydrogen carbonate solution followed by brine, and concentrated under reduced pressure. An aqueous $50 \%$ methanol $\left(\mathrm{CH}_{3} \mathrm{OH}\right)$ solution $(\mathrm{v} / \mathrm{v})$ was added to the residue and filtrated with a membrane filter. The obtained mixture was analyzed by a high-performance liquid chromatograph (HPLC, LC-10A, Shimadzu Co., Kyoto, Japan) equipped with an SPD-M10A detector (Shimadzu Co.), using the absorbance at $280 \mathrm{~nm}$. 
Conditions of HPLC were as follows. Column: Luna 5u C18 (2) 100A (150 mm $\times 4.6 \mathrm{~mm}$, Phenomenex Inc., Torrance, CA, USA); oven temperature: $40^{\circ} \mathrm{C}$; flow rate: $0.2 \mathrm{~mL} / \mathrm{min}$; solvent system: gradient $\mathrm{CH}_{3} \mathrm{OH} / \mathrm{H}_{2} \mathrm{O}(\mathrm{v} / \mathrm{v})$ from $30 / 70$ to $40 / 60$ for $30 \mathrm{~min}$ and maintained for $15 \mathrm{~min}$, total time $45 \mathrm{~min}$.

\section{Oxidation in permanganate systems}

As an acidic reaction, either compound $\boldsymbol{I E}$ or $\boldsymbol{1 T}$ was dissolved in $24.6 \mathrm{~mL}$ of sulfate buffer solution $(0.50 \mathrm{~mol} / \mathrm{L}$, $\mathrm{pH}$ 2.0). To this buffer solution was added $0.40 \mathrm{~mL}$ of $20 \mathrm{mmol} / \mathrm{L}$ potassium permanganate $\left(\mathrm{KMnO}_{4}\right)$ solution to initiate the reaction. The reaction was conducted at room temperature. The initial concentrations of compound $\boldsymbol{I E}$ (or 1T) and $\mathrm{KMnO}_{4}$ were 0.20 and $0.32 \mathrm{mmol} / \mathrm{L}$, respectively.

As a neutral reaction, either compound $\boldsymbol{I E}$ or $\boldsymbol{I T}$ was dissolved in $23 \mathrm{~mL}$ of water ( $\mathrm{pH} \mathrm{6.3)}$ ). To this solution was added $2.0 \mathrm{~mL}$ of $20 \mathrm{mmol} / \mathrm{L} \mathrm{KMnO}_{4}$ solution to initiate the reaction. The reaction was conducted at room temperature. The initial concentrations of compound $\boldsymbol{I E}$ (or $\mathbf{I T}$ ) and $\mathrm{KMnO}_{4}$ were 0.20 and $1.6 \mathrm{mmol} / \mathrm{L}$, respectively.

A portion of the reaction solution was withdrawn to quantify the surviving compound $\boldsymbol{I E}$ or $\boldsymbol{I T}$ at prescribed reaction times. The detailed workup procedures for quantification and conditions for the HPLC analysis were the same as described above for the $\mathrm{MnO}_{2}$ system.

\section{Results and discussion}

\section{Oxidation in hypochlorite systems}

Figure 2 a shows the degradation of compound $\boldsymbol{I E}$ or $\boldsymbol{I T}$ when either compound was individually (twice each) or both compounds were together (once) reacted at an alkaline $\mathrm{pH}$ of 13.3 and $70{ }^{\circ} \mathrm{C}$. Any observed degradation was always less than $5 \%$ at the end of the reaction $(60 \mathrm{~min})$. No clear difference was observed in the degradations between compounds $\boldsymbol{I E}$ and $\boldsymbol{I T}$. An iodometric titration confirmed almost no consumption of the oxidation power at the end of the reaction. Because hypochlorite anion $\left(\mathrm{ClO}^{-}\right)$rather than hypochlorous acid $(\mathrm{HClO})$ existed as the major species due to the $\mathrm{p} K_{\mathrm{a}}$ value of $\mathrm{HClO}\left(7.58\right.$ at $\left.20^{\circ} \mathrm{C}[14]\right)$, the result indicates that $\mathrm{ClO}^{-}$is rather stable under the conditions and compounds $\boldsymbol{I E}$ and $\boldsymbol{I T}$ do not have any good reaction sites with $\mathrm{ClO}^{-}$.

Figure $2 \mathrm{~b}$ shows the degradation of compound $\mathbf{I E}$ or $\mathbf{I T}$ when either compound was individually (once each) or both compounds were together (once) reacted at a neutral $\mathrm{pH}$ of 6.3 and $70{ }^{\circ} \mathrm{C}$. Any observed degradation was rapid, with complete disappearance at a reaction time of about $40 \mathrm{~min}$. No clear difference was observed in the degradations between compounds $\mathbf{I E}$ and $\mathbf{I T}$. $\mathrm{HClO}$ rather than $\mathrm{ClO}^{-}$

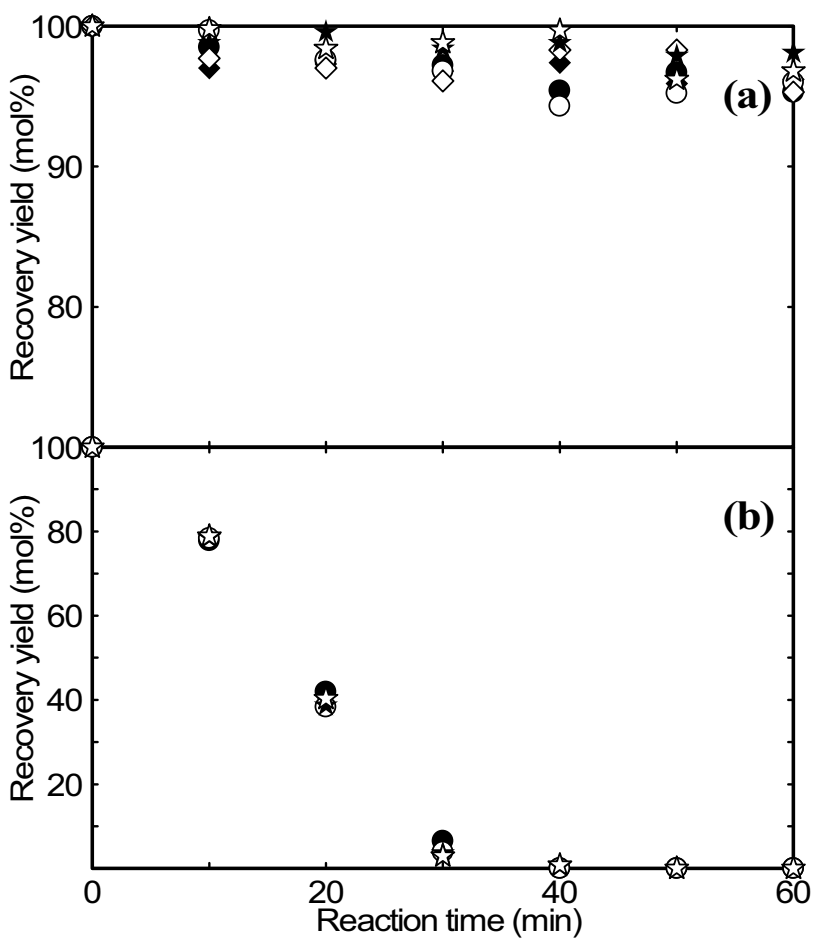

Fig. 2 Time courses of the changes in the recovery yields of compounds $1 E$ and $I T$, when either compound was individually or both compounds were together treated in the hypochlorite system at a $\mathrm{pH}$ of: a 13.3 and $70{ }^{\circ} \mathrm{C}$ or b 6.3 and $70{ }^{\circ} \mathrm{C}$. Compound $\boldsymbol{I E}$ : filled circle, filled diamond, filled star; compound $1 T$ : open circle, open diamond, open star; in the individual reaction of compound $\mathbf{I E}$ or $\mathbf{I T}$ : filled circle, filled diamond, open circle, open diamond; in the reaction of both compounds $\boldsymbol{I E}$ and $\boldsymbol{I T}$ together: filled star, open star

existed as the major species due to the $\mathrm{p} K_{\mathrm{a}}$ value. A possible reaction mechanism is nucleophilic attack of a nucleophile on the $\mathrm{Cl}$ atom of $\mathrm{HClO}$, which is essentially the reaction of chlorine cation $\left(\mathrm{Cl}^{+}\right)$with the nucleophile. The aromatic ring of compound $1 \boldsymbol{E}$ or $\boldsymbol{I T}$ is a more plausible candidate for the nucleophile than the side chain portion. This would explain why no clear stereo-preference was observed in the reaction with compound $\boldsymbol{I E}$ or $\boldsymbol{I T}$, each of which has a stereo-structurally different side chain. Both compounds $\boldsymbol{I E}$ and $\boldsymbol{I T}$ were stable without the addition of $\mathrm{NaClO}$ under these conditions.

Both compounds $\boldsymbol{I E}$ and $\mathbf{I T}$ were together reacted at an acidic $\mathrm{pH}$ of 1.0 and room temperature (twice). Because the degradation was quite rapid in a preliminary experiment, room temperature was employed (data not shown). The degradation was still fast, and the recovery yields were 6 and $3 \%$, respectively, at the first sampling time (10 $\mathrm{min})$. This result indicates that compounds $\boldsymbol{I E}$ and $\boldsymbol{I T}$ were efficiently oxidized. However, the difference was not large enough to safely state that compound $\boldsymbol{I T}$ was stereo-preferentially degraded rather than compound $\boldsymbol{I E}$. Generally, molecular chlorine $\left(\mathrm{Cl}_{2}\right)$ is generated when $\mathrm{HClO}$ reacts with hydrogen chloride $(\mathrm{HCl})$ at a low $\mathrm{pH}$. Because $\mathrm{H}_{2} \mathrm{SO}_{4}$ was used 
for the $\mathrm{pH}$ adjustment, little generation of $\mathrm{Cl}_{2}$ took place. A nucleophilic attack of the aromatic ring to the $\mathrm{Cl}$ atom of $\mathrm{HClO}$ would be a possible major reaction, similar to the above-described reaction at the neutral $\mathrm{pH}$. However, this attack would be more rapid than that at the neutral $\mathrm{pH}$ due to the protonation of $\mathrm{HClO}$ at the acidic $\mathrm{pH}\left(\mathrm{H}_{2} \mathrm{O}^{+} \mathrm{Cl}\right)$ and consequent increase of the electrophilicity of the $\mathrm{Cl}$ atom. This would result in the efficient oxidation of compounds $\mathbf{I E}$ and $\boldsymbol{I T}$ and a lack of stereo-preferential degradation. Both compounds $\boldsymbol{I E}$ and $\boldsymbol{I T}$ were rather stable without the addition of $\mathrm{NaClO}$ under these conditions.

\section{Oxidation in chlorite systems}

Figure 3 a shows the degradation of compound $\mathbf{I E}$ or $\mathbf{I T}$ when either compound was individually (once each) or both compounds were together (once) reacted at an alkaline $\mathrm{pH}$ of 13.3 and $70{ }^{\circ} \mathrm{C}$. Any observed degradation was less than 5\% at the end of the reaction. No clear difference was observed in the degradations between compounds $1 E$ and $1 T$. An iodometric titration confirmed almost no consumption of the oxidation power at the end of the reaction. Because chlorite anion $\left(\mathrm{ClO}_{2}^{-}\right)$rather than chlorous acid $\left(\mathrm{HClO}_{2}\right)$ existed as the major species due to the $\mathrm{p} K_{\mathrm{a}}$ value $\left(1.94\right.$ at $25^{\circ} \mathrm{C}$ [15]), the result indicates that $\mathrm{ClO}_{2}^{-}$is rather stable under these conditions and compounds $\boldsymbol{I E}$ and $\boldsymbol{I T}$ do not have any good reaction sites with $\mathrm{ClO}_{2}^{-}$.

Figure $3 \mathrm{~b}$ shows the degradation of compound $\boldsymbol{I E}$ or $\mathbf{I T}$ when either compound was individually reacted at a neutral $\mathrm{pH}$ of 6.3 and $70{ }^{\circ} \mathrm{C}$ (thrice each). The degradation was relatively rapid until a reaction time of about $40 \mathrm{~min}$ and accelerated during this period. (This period is hereafter described as 'the period of rapid degradation'.) After the final addition of $\mathrm{NaClO}_{2}$ at a reaction time of $40 \mathrm{~min}$, slower but continuous degradation was observed until the reaction was terminated at a reaction time of $60 \mathrm{~min}$ ('the period of slower degradation'). No clear difference was observed in the degradations between compounds $\boldsymbol{I E}$ and $\boldsymbol{I T}$ in the period of rapid degradation, while a difference gradually appeared with slight stereo-preferential degradation of compound $\mathbf{I T}$ in the period of slower degradation. It is generally considered that chlorine dioxide $\left(\mathrm{ClO}_{2}\right)$ is generated by the disproportionation of $\mathrm{ClO}_{2}{ }^{-}$or other similar reactions as the most active species, although other chlorine-related oxidants are also produced. On the basis of the obtained results, we suggest that $\mathrm{ClO}_{2}$ as well as other chlorine-related oxidants attacks compound $\boldsymbol{I E}$ or $\mathbf{I T}$ without any clear stereo-preference in the period of rapid degradation and the formation of $\mathrm{ClO}_{2}$ as well as other chlorine-related oxidants from $\mathrm{ClO}_{2}^{-}$(rather than from $\mathrm{HClO}_{2}$ due to the $\mathrm{p} K_{\mathrm{a}}$ value) accelerates with the progress of the reaction. Because the major oxidant $\mathrm{ClO}_{2}$ is a radical and preferably adds to aromatic nucleus of an

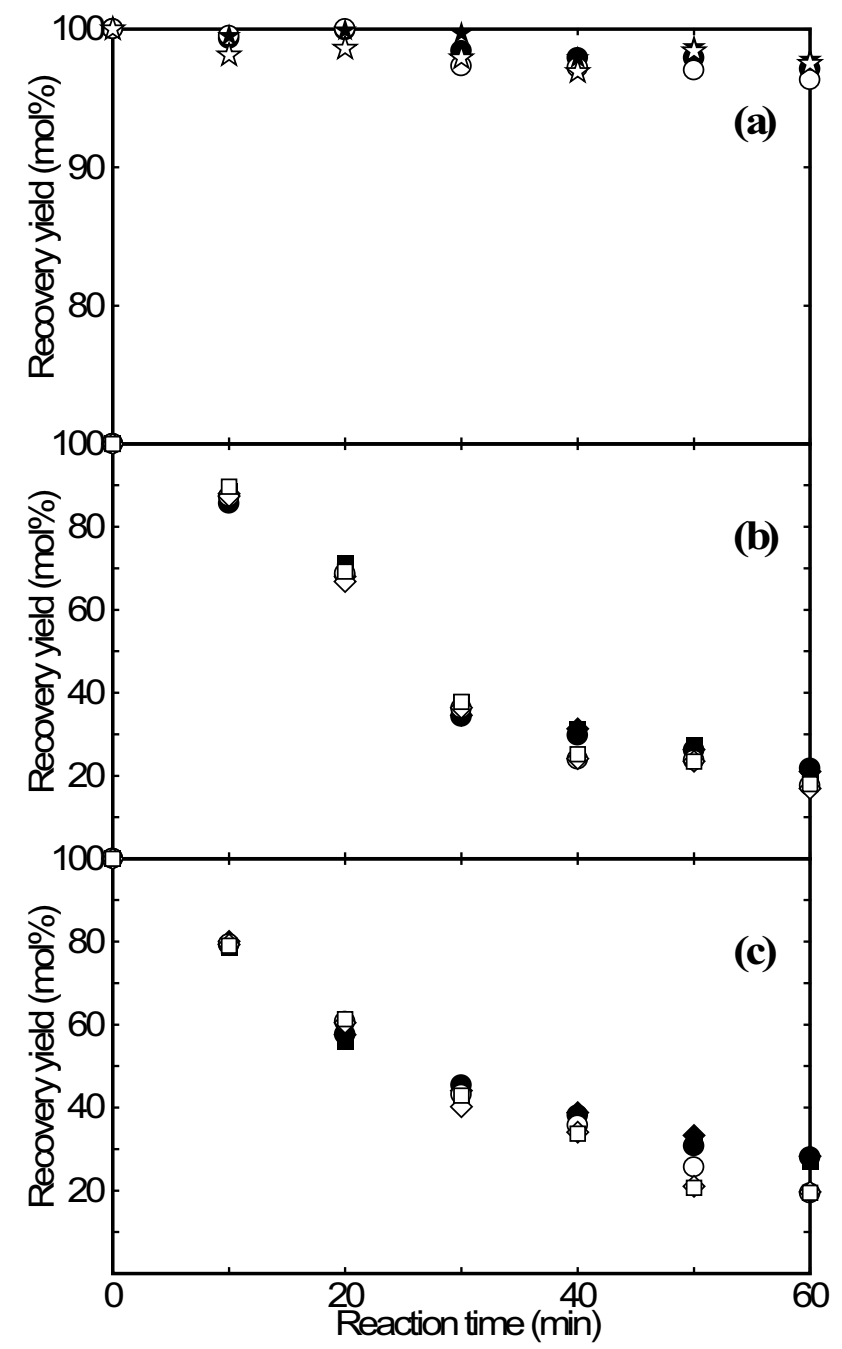

Fig. 3 Time courses of the changes in the recovery yields of compounds $\boldsymbol{I E}$ and $\boldsymbol{I T}$, when either compound was individually or both compounds were together treated in the chlorite system at a pH of: a 13.3 and $70{ }^{\circ} \mathrm{C}$, b 6.3 and $70{ }^{\circ} \mathrm{C}$, or c 1.0 and $70{ }^{\circ} \mathrm{C}$. Compound $\mathbf{E E}$ : filled circle, filled diamond, filled square, filled star; compound $1 T$ : open circle, open diamond, open square, open star; in the individual reaction of compound $\mathbf{I E}$ or $\mathbf{I T}$ : filled circle, filled diamond, filled square, open circle, open diamond, open square; in the reaction of both compounds $\boldsymbol{I E}$ and $\boldsymbol{I T}$ together: filled star, open star

aromatic substrate including lignin model compounds as an electrophile accompanied by the liberation of $\mathrm{ClO}_{2}{ }^{-}$or $\mathrm{HClO}_{2}$ (depending on $\mathrm{pH}$ ) and generation of an aromatic radical cation [16-19], it is natural that no clear stereopreference was observed in the period of rapid degradation. It is unclear, on the other hand, why the slight $\boldsymbol{T}$ stereo-preference was observed in the period of slower degradation. Some oxidants generated from $\mathrm{ClO}_{2}^{-}, \mathrm{ClO}_{2}$, and others would still exist in the period of slower degradation, and show the slight $\boldsymbol{T}$ stereo-preference. Both compounds $\boldsymbol{I E}$ and $\boldsymbol{I T}$ were stable without the addition of $\mathrm{NaClO}_{2}$ under these conditions. 
Figure $3 \mathrm{c}$ shows the degradation of compound $\boldsymbol{I E}$ or $\boldsymbol{I T}$ when either compound was individually reacted at an acidic $\mathrm{pH}$ of 1.0 and $70^{\circ} \mathrm{C}$ (thrice each). Although the degradation of each compound was similar to that observed at the neutral $\mathrm{pH}$, the following observations were different from those at the neutral $\mathrm{pH}$. (1) The degradation was slightly slower than that at the neutral $\mathrm{pH}$, and acceleration of the degradation was not observed in the period of rapid degradation. (2) The degradation of compound $\boldsymbol{I T}$ was slightly greater than that at the neutral $\mathrm{pH}$ in the period of slower degradation, and the difference in the degradations between compounds $\boldsymbol{I E}$ and $\mathbf{I T}$ was larger than that at the neutral $\mathrm{pH}$. Observation (1) may indicate that the generation of $\mathrm{ClO}_{2}$ does not exactly follow the same mechanism as that at the neutral $\mathrm{pH}$. $\mathrm{HClO}_{2}$ was the main species rather than $\mathrm{ClO}_{2}{ }^{-}$at the acidic $\mathrm{pH}$ due to the $\mathrm{p} K_{\mathrm{a}}$ value, which might result in different formation mechanisms of $\mathrm{ClO}_{2}$ from that at the neutral $\mathrm{pH}$. Observation (2) suggests that the profile of oxidants responsible for the degradation of compound $\boldsymbol{I E}$ or $\boldsymbol{I T}$ was not exactly the same as that at the neutral $\mathrm{pH}$. In accordance with the expectation on the basis of the description in the previous paragraph, no clear stereo-preference was observed in the period of rapid degradation. Both compounds $\boldsymbol{I E}$ and $\boldsymbol{I T}$ were rather stable without the addition of $\mathrm{NaClO}_{2}$ under these conditions.

\section{Oxidation in a manganese dioxide system}

Figure 4 shows the degradation of compound $\boldsymbol{I E}$ or $\boldsymbol{I T}$ when either compound was individually reacted at a $\mathrm{pH}$ of 1.0 and room temperature (thrice each). The degradation of compound $\boldsymbol{I T}$ was clearly more rapid than that of compound $\boldsymbol{I E}$, which indicates that the stereo-preference of $\mathrm{MnO}_{2}$ is the $\boldsymbol{T}$ isomer. Because $\mathrm{MnO}_{2}$ oxidized compound $\boldsymbol{I E}$ or $\boldsymbol{I T}$

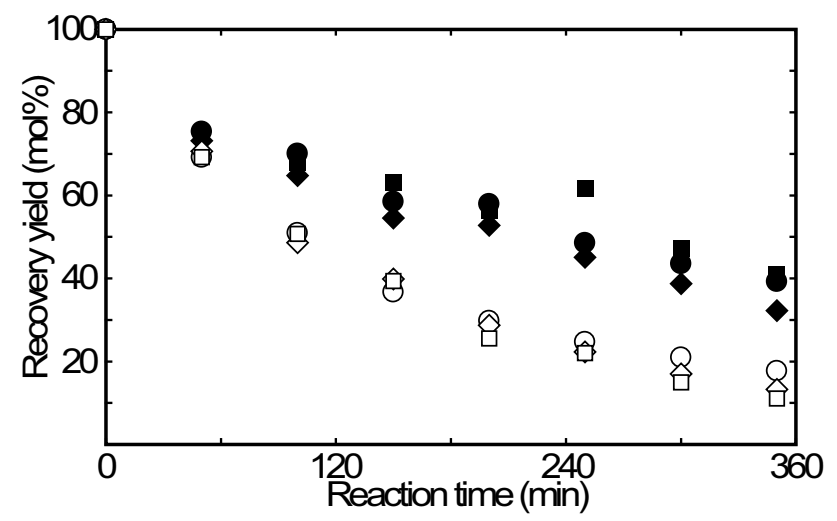

Fig. 4 Time course of the change in the recovery yield of compound $\boldsymbol{I E}$ or $\boldsymbol{I T}$, when either compound was individually treated in the manganese dioxide system at a $\mathrm{pH}$ of 1.0 and room temperature. Compound $1 E$ : filled circle, filled diamond, filled square; compound $\mathbf{I T}$ : open circle, open diamond, open square as large precipitating aggregates, it can be understood that the stereo-structure of the side chain affects the reaction rate. It is presumed that $\mathrm{MnO}_{2}$ aggregates are able to approach compound $\mathbf{I T}$ more easily than compound $\boldsymbol{I E}$ due to the stereo-structure of the side chain. The obtained results, however, are not sufficient to rule out the possibility that the stereo-preference of $\mathrm{MnO}_{2}$ observed here is dependent on a particular structure of the aggregates and that other $\mathrm{MnO}_{2}$ aggregates prepared by other methods show the reverse or almost no stereo-preference.

\section{Oxidation in permanganate systems}

Figure $5 \mathrm{a}, \mathrm{b}$ shows the degradation of compound $\mathbf{I E}$ or $\mathbf{1 T}$ when either compound was individually reacted at a $\mathrm{pH}$ of 2.0 or 6.3 , respectively, and room temperature. Because the degradation was too rapid to follow at a $\mathrm{pH}$ of 1.0 using a large excess of $\mathrm{KMnO}_{4}$ in a preliminary experiment, the applied $\mathrm{pH}$ was 2.0 and the molar ratio of $\mathrm{KMnO}_{4}$ to compound $\boldsymbol{I E}$ or $\boldsymbol{I T}$ was 1.6 in the acidic system. The molar ratio of $\mathrm{KMnO}_{4}$ to compound $\boldsymbol{I E}$ or $\boldsymbol{I T}$ was 8.0 at a $\mathrm{pH}$ of 6.3.

The degradation of compound $\boldsymbol{I T}$ was clearly greater than that of compound $\boldsymbol{I E}$ at a $\mathrm{pH}$ of 2.0. It is possible to assume that $\mathrm{MnO}_{2}$ was generated as an intermediate at this $\mathrm{pH}$ and

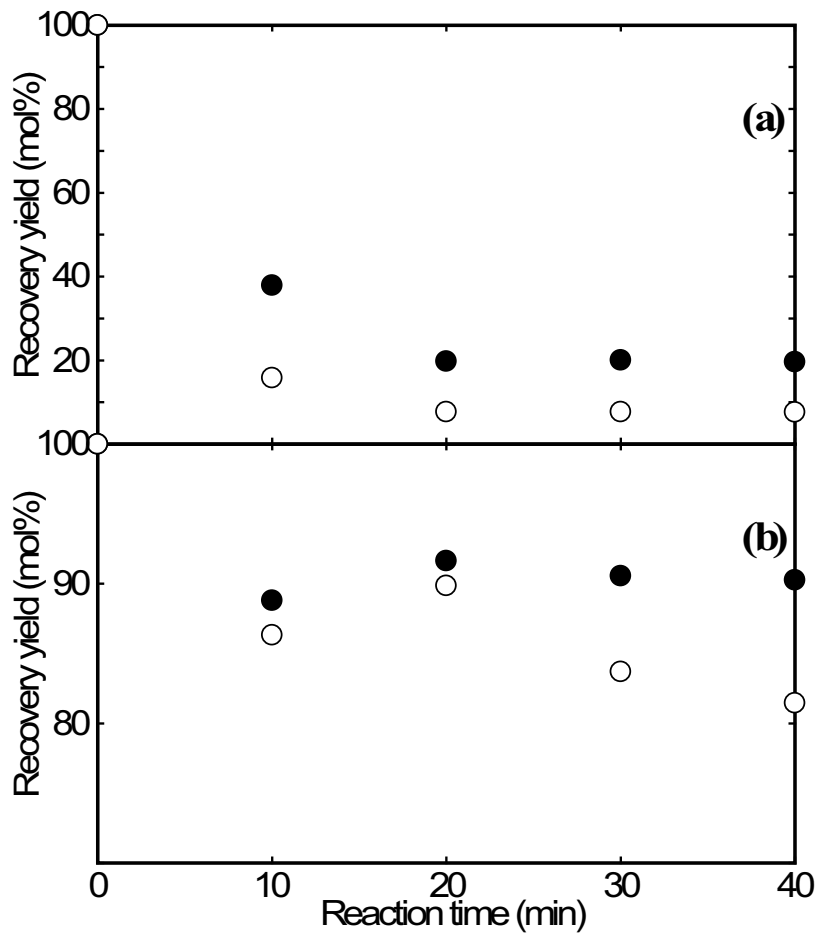

Fig. 5 Time course of the change in the recovery yield of compound $\boldsymbol{I E}$ or $\boldsymbol{I T}$, when either compound was individually treated in the permanganate system at a $\mathrm{pH}$ of: $\mathbf{a} 2.0$ and room temperature or $\mathbf{b} 6.3$ and room temperature. Compound $\mathbf{I E}$ : filled circle; compound $\mathbf{I T}$ : open square 
co-oxidized compound $\boldsymbol{I E}$ or $\boldsymbol{I T}$, although the half-reaction of permanganate $\left(\mathrm{MnO}_{4}^{-}\right)$in an acidic medium is described as: $\mathrm{MnO}_{4}^{-}+8 \mathrm{H}^{+}+5 \mathrm{e}^{-} \rightarrow \mathrm{Mn}^{2+}+4 \mathrm{H}_{2} \mathrm{O}$. Because the $\mathrm{MnO}_{2}$ oxidation of compound $\boldsymbol{I E}$ or $\mathbf{I T}$ was confirmed to be much slower than the observed oxidation rate at the $\mathrm{pH}$, the observed $\boldsymbol{T}$ stereo-preference is concluded to be due to the reaction of $\mathrm{MnO}_{4}{ }^{-}$at the $\mathrm{pH}$ without the effect of $\mathrm{MnO}_{2}$. Because the oxidation system was homogeneous differently from that of $\mathrm{MnO}_{2}$ and it is commonly believed that the oxidation mechanism of $\mathrm{MnO}_{4}{ }^{-}$is the attack on an electron rich double bond, aromatic nucleus, etc., the effect of the stereo-structure of the side chain on the $\mathrm{MnO}_{4}{ }^{-}$oxidation cannot easily be explained. The large size of $\mathrm{MnO}_{4}^{-}$may possibly relate to the $\boldsymbol{T}$ stereo-preference, resulting in the side chain of compound $\mathbf{I T}$ being more ready than that of compound $\boldsymbol{I E}$ to interact with $\mathrm{MnO}_{4}^{-}$.

The degradation of compound $\mathbf{1 T}$ was also greater than that of compound $\mathbf{I E}$ at a $\mathrm{pH}$ of 6.3 , although the degradation was not great. The half-reaction of $\mathrm{MnO}_{4}^{-}$in a neutral medium is described as: $\mathrm{MnO}_{4}^{-}+4 \mathrm{H}^{+}+3 \mathrm{e}^{-} \rightarrow \mathrm{MnO}_{2}+2 \mathrm{H}_{2} \mathrm{O}$, which explains the observed slow oxidation at this $\mathrm{pH}$ due to the requirement for $\mathrm{H}^{+}$. Because the degradation of compound $\boldsymbol{I E}$ or $\boldsymbol{I T}$ was not great and was observed only at an early stage of the reaction in spite of the application of 8 times mole amount of $\mathrm{KMnO}_{4}$, some degradation products might have been oxidized by $\mathrm{MnO}_{4}{ }^{-}$more easily than compound $\boldsymbol{I E}$ or $\boldsymbol{I T}$. The $\boldsymbol{T}$ stereo-preference is not easily explainable, either.

\section{Conclusions}

The erythro $(\boldsymbol{E})$ or threo $(\boldsymbol{T})$ isomer of the most common non-phenolic $\beta$-O-4-type lignin model compound was individually or both isomers together oxidized in hypochlorite, chlorite, manganese dioxide, or permanganate systems to examine which isomer was stereo-preferentially oxidized. No stereo-preference was observed in any hypochlorite or chlorite system at any applied $\mathrm{pH}$ except in the later stage of the chlorite system at neutral or acidic $\mathrm{pH}$, where the stereopreferential degradation of the $\boldsymbol{T}$ isomer was observed in this later stage. Stereo-preferential degradation of the $\boldsymbol{T}$ isomer was also observed in the manganese dioxide and permanganate systems. These stereo-preferences cannot easily be explained, although some of them may possibly result from the ease of approach of the oxidant to the $\boldsymbol{T}$ isomer rather than to the $\boldsymbol{E}$ isomer.

\section{References}

1. Miksche GE (1972) Zum alkalischen abbau der $p$-alkoxyarylglycerin- $\beta$-arylätherstrukturen des lignins: Versuche mit erythro-veratrylglycerin- $\beta$-guajacyläther (In German). Acta Chem Scand 26(8):3275-3281

2. Tsutsumi Y, Kondo R, Imamura H (1993) Reaction of syringylglycerol- $\beta$-syringyl ether type of lignin model compounds in alkaline-medium. J Wood Chem Technol 13(1):25-42

3. Criss DL, Elder T, Fisher TH, Schultz TP (2002) Effect of the $\alpha$-and $\gamma$-hydroxyls on the alkaline hydrolysis rate of nonphenolic $\beta$-O-4 lignin diastereomers. Holzforschung 56(1):67-72

4. Shimizu S, Yokoyama T, Akiyama T, Matsumoto Y (2012) Reactivity of lignin with different composition of aromatic syringyl/guaiacyl structures and erythro/threo side chain structures in $\beta-O-4$ type during alkaline delignification: as a basis for the different degradability of hardwood and softwood lignin. J Agric Food Chem 60(26):6471-6476

5. Shimizu S, Posoknistakul P, Yokoyama T, Matsumoto $\mathrm{Y}$ (2013) Quantitative difference in the rates of the $\beta-O-4$ bond cleavage between lignin model compounds with and without $\gamma$-hydroxymethyl groups during the alkaline pulping process. BioResources 8(3):4312-4322

6. Shimizu S, Yokoyama T, Matsumoto Y (2015) Effect of type of aromatic nucleus in lignin on the rate of the $\beta-O-4$ bond cleavage during alkaline pulping process. J Wood Sci 61(5):529-536

7. Jonsson L, Karlsson O, Lundquist K, Nyman PO (1990) Stereospecificity in enzymic and non-enzymic oxidation of $\beta-O-4$ lignin model compounds. FEBS Lett 276(1\&2): 45-48

8. Bohlin C, Andersson PO, Lundquist K, Jonsson LJ (2007) Differences in stereo-preference in the oxidative degradation of diastereomers of the lignin model compound 1-(3,4-dimethoxyphenyl)-2-(2-methoxyphenoxy)-1,3-propanediol with enzymic and non-enzymic oxidants. J Mol Catal B Enzym 45(1\&2): 21-26

9. Bohlin C, Lundquist K, Jonsson LJ (2009) Oxidation of the erythro and threo forms of the phenolic lignin model compound 1-(4-hydroxy-3-methoxyphenyl)-2-(2-methoxyphenoxy)1,3 -propanediol by laccases and model oxidants. Bioorg Chem 37(5):143-148

10. Sugimoto T, Akiyama T, Matsumoto Y, Meshitsuka G (2002) The erythrolthreo ratio of $\beta-O-4$ structures as an important structural characteristic of lignin. Part 2: Changes in erythro/threo $(\mathrm{E} / \mathrm{T})$ ratio of $\beta-O-4$ structures during delignification reactions. Holzforschung 56(4):416-421

11. Posoknistakul P, Akiyama T, Yokoyama T, Matsumoto Y (2016) Stereo-preference in the degradation of the erythro and threo isomers of $\beta$-O-4-type lignin model compounds in oxidation processes Part 1: In the reaction with active oxygen species under oxygen delignification conditions. J Wood Chem Technol 36(4):288-303

12. Posoknistakul P, Akiyama T, Yokoyama T, Matsumoto Y (2017) Stereo-preference in the degradation of the erythro and threo isomers of $\beta$-O-4-type lignin model compounds in oxidation processes Part 2: In the reaction with hydroxyl and oxygen anion radicals under hydrogen peroxide bleaching conditions. J Wood Chem Technol 37(2):87-98

13. Posoknistakul P, Akiyama T, Yokoyama T, Matsumoto Y (2017) Predominant formation of aromatic aldehyde and acid form a dimeric $\beta$-O-4-type lignin model compound under hydrogen peroxide bleaching conditions with high $\mathrm{pH}$ levels. J Wood Sci 63(2):173-182

14. Morris JC (1966) The acid ionization constant of $\mathrm{HOCl}$ from $5^{\circ}$ to $35^{\circ}$. J Phy Chem 70(12):3798-3805

15. Perrin DD (1982) Ionisation constants of inorganic acids and bases in aqueous solution, 2nd edn. Pergamon, Oxford

16. Grimley E, Gordo G (1973) The kinetics and mechanism of the reaction between chlorine dioxide and phenol in acidic aqueous solution. J Inorg Nucl Chem 35(7):2383-2392 
17. Gierer J (1990) Basic principles of bleaching Part 1: cationic and radical processes. Holzforshung 44(5):387-394

18. Brage C, Eriksson T, Gierer J (1991) Reactions of chlorine dioxide with lignins in unbleached pulps Part 1. Holzforshung 45(1):23-30
19. Brage C, Eriksson T, Gierer J (1991) Reactions of chlorine dioxide with lignins in unbleached pulps Part 2. Holzforshung 45(2):147-152 